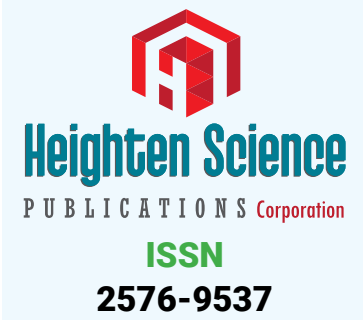

*Address for Correspondence: Mohamed Abdelhamid, Surgery Department, Faculty of Medicine, Beni Suef, Egypt, Tel: 00201062531899; Email:m.salah10.59@gmail.com; mohamedsalah_2000@hotmail.com

Submitted: 27 December 2018

Approved: 23 January 2019

Published: 24 January 2019

Copyright: (c) 2019 Abdelhamid MS, et al. This is an open access article distributed under the Creative Commons Attribution License, which permits unrestricted use, distribution, and reproduction in any medium, provided the original work is properly cited

Keywords: TAPP Lichtenstein PHS

Check for updates
Research Article

\section{Trans Abdominal Pre-Peritoneal (TAPP) mesh for Inguinal Hernia Repair with External Fixation [Abdelhamid Technique], Outcome Assessment}

\author{
MS Abdelhamid ${ }^{1 *}$, TM Nabil ${ }^{1}$, HA Nafady ${ }^{1}$, AM Bekeet ${ }^{1}$, AZ \\ Garib $^{3}$, MA Negida² and SS Soliman ${ }^{4}$ \\ ${ }^{1}$ Surgery Department, Faculty of Medicine, Beni Suef, Egypt \\ ${ }^{2}$ Surgery Department, Kasr El Aini Teaching Hospital, Faculty of Medicine, Egypt \\ ${ }^{3}$ Surgery Department, October $6{ }^{\text {th }}$ Faculty of Medicine, Giza, Egypt \\ ${ }^{4}$ Surgery Department, Faculty of Medicine, Fayoum, Egypt
}

\section{Abstract}

Purpose: To compare the outcomes of Abdelhamid technique in treatment of inguinal hernia to conventional TAPP with mesh stapling, Prolene hernia system (PHS) and Lichtenstein repair.

Background: the mesh is applied and fixed externally aiding in decreasing port size and cost. There is controversy concerning the necessity of securing the mesh during laparoscopic TAPP repair.

Patients: The study was carried out at the faculty of medicine - Beni Suef University, Egypt from September 2008 to April 2018. 672 patients with unilateral inguinal hernia participated in the study. 432 were treated using Abdelhamid Technique, 382 of which were unilateral primary inguinal hernia and 50 were unilateral recurrent. 50 patients were treated using Prolene Hernia System (PHS). 50 patients with recurrent hernias were treated using Lichtenstein repair and 140 patients went TAPP with mesh stapling.

Results: Abdelhamid technique showed more cost effectiveness than stapling (1800\$ vs $3000 \$)$, pronounced less recurrence rate in comparison with Liechtenstein and PHS (2\% vs $4 \%$ ), same LOS compared to other techniques and mean operative time of 76 minutes which is longer than stapling (60 mins), Liechtenstein (65 mins) and PHS (55 mins).

Conclusion: Abdelhamid technique was a more lengthy operation costing more than open surgery but less than mesh stapling. The recurrence rate is considerably reduced with shorter recovery period. The technique is done with smaller port size that leads to cost reduction. 
internal oblique and transversus abdominis muscles superiorly rectus abdominis muscle medially, iliopsoas muscle laterally and inferiorly by Cooper ligament and the pubis. It is bisected by the inguinal ligament and covered by the fascia transversalis [6]. Hernia recurrence may be due to tight repair, weak reparative tissue, incomplete repair or mostly a missed sac [7]. LIHR is favored over open hernia repair (OHR) as it is associated with lower pain levels, lower chance of infection, lower recurrence rate and shorter recovery period. With sufficient operator's skill and experience, TAPP would be a safe treatment option that results in patient satisfaction $[8,9]$.

Abdelhamid technique holds numerous advantages that marks it as a very agreeable treatment option. In this technique the internal fixation of the mesh is not an absolute necessity which aids in a considerable cost reduction, the external fixation is safely performed with decreased port size and reduced pain [10]. Since no tuckers nor staples are used in Abdelhamid technique, the chances for nerve entrapment is decreased minimizing the associated groin pain compared to TAPP with internal fixation [11]. However, the higher cost [12] and longer OR time [13], still are associated with the procedure.

\section{Patients}

The study was carried out at the faculty of medicine - Beni Suef University, Egypt from September 2008 to April 2018. 672 patients with unilateral inguinal hernia participated in the study. 432 were treated using Abdelhamid Technique, 382 of which were unilateral primary inguinal hernia and 50 were unilateral recurrent. 50 patients were treated using Prolene Hernia System (PHS). 50 patients with recurrent hernias were treated using Lichtenstein repair and 140 patients went TAPP with mesh stapling.

\section{Methods}

\section{TAPP}

Conventional Trans abdominal preperitoneal mesh with internal fixation was performed to 140 patients.

\section{Abdelhamid technique}

The technique was performed to 432 patients in whom the mesh was fixed to the outside with two prolene threads. $8 \times 12 \mathrm{~cm}$ mesh was used to cover the myopectineal orifice applied on lay on the cord [10].

\section{PHS}

The underlay mesh is the passed to the outside of the defect and adapted under the floor of the canal in the preperitoneal space. The mesh connector plugs the defect to secure it and prevent recurrence. The onlay patch is then adapted over the floor of the canal and modified to accommodate the surrounding structures [14,15].

\section{Lichtenstein}

The surgical mesh acts as a scaffold for growth of new tissue to reinforce the abdominal wall. Later on, the mesh becomes embedded in the muscle layer, creating a strong repair. A polypropylene mesh ( $3 \times 5 \mathrm{inch})$ is adjusted to fit the floor of the inguinal canal and its edges are sutured to the pubic tubercle using a No 3-0 Prolene suture. The same continuous suture then carries on to the lower border of the mesh to the free edge of the inguinal ligament after an opening is prepared into its lower edge to allow passage of the spermatic cord [16].

\section{Results}

Since we started our technique, we conducted five consecutive studies.

1- Transabdominal pre-peritoneal inguinal hernia repair with external fixation (Table 1) [10]. 
2- Transabdominal Pre-Peritoneal Mesh for Inguinal Hernia Repair with External Fixation versus Mesh Stapling (Table 2) [12].

3- Patients Satisfaction Post Laparoscopic Transabdominal Preperitoneal Inguinal Hernia Repair with External Fixation versus Post Internal Fixation (Table 2) [11].

4- Transabdominal pre-peritoneal inguinal hernia repair with external fixation (ABDELHAMID TECHNIQUE) versus Lichtenstein for repair of recurrent inguinal hernia (Table 3) [13].

5- Primary Inguinal Hernia Repair Using TAPP with External Fixation (Abdelhamid Technique) Versus Prolene Hernia System (Table 4) [17].

\section{Discussion}

The chances for recurrence can be decreased to the minimum by fixation until occurrence of fibrous tissue formation. Using repair tissue in the repair after recurrence has already occurred is illogic [18]. LIHR goes beyond this scarred tissue. Stapling the mesh can be eliminated and help decrease the cost $[17,19]$.

Abdelhamid technique may be considered an excellent choice as it offers both efficient fixation and lower cost. The problem of mesh transportation due to a nonfixation technique was not faced during this study. Lower pain levels post operatively was also gained due to the elimination of the need to a $12 \mathrm{~mm}$ port. The issue of nerve entrapment associated with the use of tuckers and staplers was also eliminated.

Table 1: Transabdominal pre-peritoneal inguinal hernia repair with external fixation.

\begin{tabular}{|c|c|}
\hline Value of & TAPP with external fixation \\
\hline OR time & 85 minutes \\
\hline Cost in $\$$ & $1800 \$$ \\
\hline LOS & $1-2$ days \\
\hline Recurrence & 0 \\
\hline Return to work in days & 7 \\
\hline
\end{tabular}

Table 2: Transabdominal Pre-Peritoneal Mesh for Inguinal Hernia Repair with External Fixation versus Mesh StaplingPatients Satisfaction Post Laparoscopic Transabdominal Preperitoneal Inguinal Hernia Repair with External Fixation Versus Post Internal Fixation ---

\begin{tabular}{|c|c|c|}
\hline Mean & TAPP with external fixation & TAPP with internal fixation \\
\hline OR time & 70 & 60 \\
\hline Cost in \$ & 1800 & 3000 \\
\hline LOS & 1 & 1 \\
\hline Recurrence & $0 / 140$ & $0 / 140$ \\
\hline Return to work & 5 & 9 \\
\hline
\end{tabular}

Table 3: Transabdominal Pre-Peritoneal (Tapp) Mesh with External Fixation (Abdelhamid Technique) versus Lichtenstein for Repair of Recurrent Inguinal Hernia

\begin{tabular}{|c|c|c|}
\hline Mean & TAPP with external fixation & Lichtenstein \\
\hline OR time & 80 & 65 \\
\hline Cost in \$ & 1800 & 500 \\
\hline LOS & 1 & 1 \\
\hline Recurrence & $1 / 50 \quad 2 \%$ & $2 / 504 \%$ \\
\hline Return to work & 5 & 9 \\
\hline
\end{tabular}

Table 4: Primary Inguinal Hernia Repair Using TAPP with External Fixation (ABDELHAMID TECHNIQUE) Versus Prolene Hernia system.

\begin{tabular}{|c|c|c|}
\hline Mean & TAPP with external fixation & PHS \\
\hline OR time & 70 & 55 \\
\hline Cost in \$ & 1800 & 1500 \\
\hline LOS & 1 & 1 \\
\hline Recurrence & $3 / 2001.5 \%$ & $2 / 504 \%$ \\
\hline Return to work & 5 & 9 \\
\hline
\end{tabular}


Abdelhamid technique had combined the benefit of fixation with less postoperative complications with lower costs and lower recurrence rate [10-13,17].

As much as preperitoneal repair seems an easy option, insertion of a mesh in the space of Bogros is associated with severe dissection. On the contrary, TAPP with external fixation guarantees an additional benefit of safety. As mesh stapling is not a necessity, noticeable decrease in cost is gained. The safer fixation and lower cost offered by Abdelhamid technique makes it of choice [12]. In addition to the cost decrease as no fixation device is needed, Abdelhamid technique is easily learned with much less groin pain in comparison with internal fixation and lower incidence of impulse of cough making it more acceptable to the patients [11].

When it comes to time consumed for the operation, the mean operative time for TAPP with external fixation was 76 minutes while in case of TAPP with mesh stapling was 60 minutes, 65 minutes for Lichtenstein and 55 minutes for PHS. This comparison of course favors Lichtenstein as the majority of patients are elderly and lengthy operations under anesthesia with abdominal insufflations should be avoided.

The cost issue is of great importance especially for the third world countries. The cost of TAPP with external fixation (Abdelhamid technique) after eliminating the need for a $12 \mathrm{~mm}$ trocar and the use of a fixing device ( tuckers or staplers) is still higher compared with Lichtenstein ( $1800 \$$ vs $500 \$)$. While in case of TAPP with mesh stapling, the cost was about $3000 \$$ and $1500 \$$ for PHS. Although Abdelhamid technique offered great cost decrease compared to traditional TAPP with mesh fixation, it is still higher than that of open surgery.

Length of stay after Abdelhamid technique was 1-2 days, later on it became one day as same as for mesh stapling, Lichtenstein and PHS.

The recovery period after Abdelhamid technique was 7 days in the first study then dropped to 5 days compared to longer periods -9 days- in both PHS and Lichtenstein. This is in favor of Abdelhamid technique and TAPP in general.

A very important outcome of Abdelhamid technique was lower recurrence rate of $2 \%$ compared to a $4 \%$ of Lichtenstein and PHS.

The early return to work doesn't quite make it up for the added costs with laparoscopic hernia repair $[20,21]$. Tissocol is a fine option for mesh fixation during TAPP [22]. However, mesh adjustment isn't an option once fixed with Tissocol. On the contrary in Abdelhamid technique, mesh adjustment is easy before its well-fixed to the anterior abdominal wall with allowance of some degree of tension. Easier application and better adaptation is offered by Abdelhamid technique as the mesh acts as a barrier against the abdominal wall and this manipulation eliminates the issue of size difference faced with internal fixation. Without this manipulation, the size of the mesh and after deflating is usually bigger than the stretched anterior abdominal wall. Again , external fixation of the mesh is of choice as it offers safe fixation and lower cost for treatment of recurrent inguinal hernias that are caused by the use of traditional (no mesh) methods. The laparoscopic method should be the first option especially for young, physically active non obese patients. In cases contraindicated for laparoscopy, Lichtenstein approach is recommended [19].

Laparoscopic TAPP repair is associated with faster recovery, less pain, less postoperative complication better cosmetic result as compared to open Lichtenstein repair [23].

Judging all the given criteria of safety, feasibility, cost, length of stay, recovery, long term symptoms and economics, LIHR using Abdelhamid technique is the winner. The technique eliminated the use of $12 \mathrm{~mm}$ trocar and any mesh fixation which are the most expensive components in the cost of TAPP hernia repair [10]. Mesh stapling is not required in the vast majority of cases thus reducing the cost [11]. 


\section{Conclusion}

It is concluded that TAPP with external fixation (Abdelhamid technique) is associated with longer operative time and higher cost in comparison with open surgery repair but less in comparison to mesh stapling. The chances for recurrence is much less with earlier return to work in Abdelhamid technique compared to open surgery making it a recommended option for treatment of primary and recurrent inguinal hernia.

\section{References}

1. Wall ML, Cherian TH, Lotz JC. Laparoscopic hernia repair-the best option? Acta Chir Belg. 2008; 108: 186-191. Ref.: https://goo.gl/LdeUjA

2. Gilbert Al, Graham MF. Improved suture less technique - advice to experts. Problems in General surgery. 1995; 12: 117-119. Ref.: https://goo.gl/fVgb3n

3. Lichtenstein IL, Shulman Ag, Amid PK, Montllor MM. The tension-free hernioplasty. Am J Surg. 1989; 157: 188-193. Ref.: https://goo.gl/UgU1cR

4. Rutkow IM, Robbins AW. Tension-free inguinal hernioplasty: preliminary reports on the mesh plug technique. Surgery. 1993; 114: 308-312. Ref.: https://goo.gl/uMGiYz

5. Fingerhut A, Millat B, Veyrie N, Chouillard E, Dziri C. Inguinal hernia repair-update 2006. In: Neugebauer EAM, Sauerland S, Fingerhut A, Millat B, Buess G (eds) EAES guidelines for endoscopic surgery. Springer. 2006; 297-309. Ref.: https://goo.gl/7dduPZ

6. Wantz GE. Abdominal wall hernias. In Schwartz SI (ed). Principles of Surgery, 6th ed.: Mc Grow-Hill, Inc., New York; 1999; 1541-1544.

7. Zoslt B, Csiky. Recurrence rate in Bassini operation after five years. Magy Seb. 2001; 54: 307-308. Ref.: https://goo.gl/x1iqtC

8. Kapiris S, Mavromatis T, Andrikopoulus S, Georgiades C, Floros D, et al. Laparoscopic transabdominal preperitoneal hernia repair (TAPP): stapling the mesh is not mandatory. $\mathrm{J}$ Laparosc Adv Surg Tech. 2009; 19: 419-422. Ref.: https://goo.gl/tP7de6

9. Ridings $P$, Evans DS. The transabdominal pre-peritoneal (TAPP) inguinal hernia repair: a trip along the learning curve. J R Coll Surg Edinb. 2000; 45: 29-32. Ref.: https://goo.gl/pXWoAp

10. Abdelhamid MS. Transabdominal Pre-Peritoneal Inguinal Hernia Repair with External Fixation Hernia. 2011; 15: 185-188. Ref.: https://goo.gl/5nfmMh

11. Abdelhamid MS, Abouleid AH, Abdelmola MH, Rashad AM, Negida MA, et al. Patients Satisfaction Post Laparoscopic Transabdominal Preperitoneal Inguinal Hernia Repair with External Fixation Versus Post Internal Fixation. Journal of Surgery. 2016; 4: 20-23. Ref.: https://goo.gl/JtTi3x

12. Abdelhamid MS, Sadat AM, Abdelhakim AF, Nabil TM, Abdelbasset MS, et al. Transabdominal PrePeritoneal Mesh for Inguinal Hernia Repair with External Fixation versus Mesh Stapling Surgical science. 2013; 4: 516-519. Ref.: https://goo.gl/yBtzmY

13. Abdelhamid MS, Nabil TM, Nafady HA, Ali AM, Rashad AM, et al. Transabdominal Preperitoneal (TAPP) Mesh With Extrenal Fixation (Abdelhamid Technique) Versus Lichtenstein For Repair of Recurrent Inguinal Hernia. International Journal of Current Research. 2017; 9: 48008-48012. Ref.: https://goo.gl/GWmGoy

14. Licheri S, Erdas E, Martinasco L, Pisano G, Pomata M, et al. Treatment of inguinal hernia with PHS. Chir Ital. 2004; 56: 127-134. Ref.: https://goo.gl/iRgrVU

15. Chandiramani VA, Katara AW, Pandyas $M$, Nair NS. PHS in the tension free repair of primary inguinal hernias. Ind J Surg. 2003; 65: 488-491. Ref.: https://goo.gl/LCCmq5

16. Sakorafas $\mathrm{GH}$, Halikias I, Nissotakis $\mathrm{C}$. Open tension free repair of inguinal hernias, the Lichtenstein technique. BMC Surgery. 2001; 1: 3-12. Ref.: https://goo.gl/fP6qtX

17. Abdelhamid MS, Nabil TM, Nafady HA, Ali AM, et al. Primary Inguinal Hernia Repair Using TAPP with External Fixation (Abdelhamid Technique) Versus Prolene Hernia System. Advances in Surgical Sciences. 2017; 5: 36-40. Ref.: https://goo.gl/BtgcGF

18. Schwab R, Schumacher $O$, Junge $K$, Binnebosel $M$, Klinge $U$, et al. Biomechanical analyses of mesh fixation in TAPP and TEP hernia repair. Surg Endosc. 2008; 22: 731-738. Ref.: https://goo.gl/24cST9

19. Choy C, Shapiro K, Patel S, Graham A, Ferzli G. Investigating a possible cause of mesh migration during totally extra peritoneal repair. Surg Endosc. 2004; 18: 523-525. Ref.: https://goo.gl/TjCrVf 
20. Demetrashvili Z, Qerqadzev V, Kamkamidze G, Topchishvil IG, Lagvilava L, et al. Comparison of Lichtenstein and Laparoscopic Transabdominal Preperitoneal Repair of Recurrent Inguinal hernias. Int Surg. 2011; 96: 233-238. Ref.: https://goo.gl/rFtA3E

21. Voyles CR, Hamilton BJ, Johnson WD, Kano N. Meta-analysis of laparoscopic inguinal hernia trials favors open hernia repair with preperitoneal prosthesis. Am J Surg. 2002; 184: 6-10. Ref.: https://goo.gl/qXqWgy

22. Olmi S, Erba L, Bertolini A, Scaini A, Croce E. Fibrin glue for mesh fixation in laparoscopic transabdominal preperitoneal (TAPP) hernia repair indications, technique and outcomes. Surg Endosc. 2006; 20: 1846-1850. Ref.: https://goo.gl/7P7ix6

23. Choudhury DK, Khan AA. A Comparative Study between Laparoscopic TAPP Repair and Lichtenstein Repair of Inguinal. IOSR Journal of Dental and Medical Sciences (IOSR-JDMS). 2016; 15: 21-23. Ref.: https://goo.gl/EQvJ4o 